disassembly in yeast cells may also hold true in metazoa. However, evidence for an essential role of SR proteins in bulk mRNA export in metazoa is lacking. Studies in C. elegans and Drosophila have raised the possibility that the recruitment of NXF1-p15 to mRNAs is mediated by multiple and partially redundant adaptor proteins (for example, Yralp orthologs and SR proteins) ${ }^{1}$. Such a variety of adaptors will probably be matched with equally diverse mechanisms regulating their interaction with the receptor. These are likely to involve ATP-driven conformational changes catalyzed by helicases or induced by binding of import receptors in the cytoplasm and post-translational modifications, all

\section{Turning on FLT3}

Protein kinases are attractive and promising drug targets in the treatment of a range of human diseases, including diabetes, muscular dystrophy and especially human cancers. The success of kinase inhibitors, Gleevec ${ }^{\mathrm{TM}}$ in particular, in the treatment of chronic myelogenous leukemia and gastrointestinal stromal tumors, has fueled research into the identification of other specific kinase inhibitors. This search is complicated however, because of the similarities among multiple kinase family members.

Identifying an inhibitor molecule that will inhibit a disease-linked kinase specifically acting in concert to disassemble an mRNP export cargo as soon as it reaches the cytoplasmic side of the NPC.

1. Suntharalingam, M. \& Wente, S.R. Dev. Cell 4, 775-789 (2003).

2. Stutz, F. \& Izaurralde, E. Trends Cell. Biol. 13, 319-327 (2003).

3. Reed, R. \& Hurt, E. Cell 108, 523-531 (2002).

4. Gilbert, W. \& Guthrie, C. Mol. Cell 13, 201-212 (2004).

5. Weis, K. Curr. Opin. Cell Biol. 14, 328-335 (2002).

6. Snay-Hodge, C.A., Colot, H.V., Goldstein, A.L. \& Cole, C.N. EMBO J. 17, 2663-2676 (1998).

7. Tseng S.S. et al. EMBO J. 17, 2651-2662 (1998).

8. Schmitt, C. et al. EMBO J. 18, $4332-4347$ (1999).

9. Maquat, L.E. Nature Rev. Mol. Cell Biol. 5, 89-99 (2004)

10. Ohno, M., Segref, A., Bachi, A., Wilm, M. \& Mattaj, I.W. Cel/ 101, 187-198 (2000).

11. Graveley, B.R. RNA 6, 1197-1211 (2000).
12. Lee, M.S., Henry, M., \& Silver, P.A. Genes Dev. 10 1233-1246 (1996)

13. Singleton, D.R., Chen, S., Hitomi, M., Kumagai, C. \& Tartakoff, A.M. J. Cell Sci. 108, 265-272 (1995).

14. Russell, I. \& Tollervey, D. Eur. J. Cell Biol. 66, 293-301 (1995).

15. Lei, E.P., Krebber, H., \& Silver, P.A. Genes Dev. 15, 1771-1782 (2001)

16. Gilbert, W., Siebel, C.W., \& Guthrie, C. RNA 7, 302-313 (2001).

17. Yun, C.Y. \& Fu,X.D. J. Cell Biol. 150, 707-718 (2000).

18. Feng, Z.H. et al. J. Biol. Chem. 266, 23796-23801 (1991).

19. Misteli, T. \& Spector, D. L. (1996). Mol. Biol. Cell. 7, 1559-1572 (1996).

20. Misteli, T. et al. J. Cell Biol. 143, 297-307 (1998).

21. Kim, E., Du, L., Bregman, D. B., and Warren, S. L. J. Cell Biol. 136, 19-28 (1997)

22. Jensen, T.H., Dower, K., Libri, D. \& Rosbash, M. Mol. Cell 11, 1129-1138 (2003).

23. Huang, Y., Gattoni, R., Stevenin, J., \& Steitz, J.A. Mol. Cell 11, 837-843 (2003). from amidst a sea of similar-looking beneficial kinases is not straightforward.

Because of this, studies aimed at understanding the molecular-level details of individual disease-linked kinases are well worth the effort. One such study, published in a recent issue of Molecular Cell (13, 169-178; 2004), reports the crystal structure of the autoinhibited form of FLT3, a type III receptor tyrosine kinase.

Type III receptor kinases are made up of an extracellular ligand binding domain, a transmembrane region and an intracellular (cytoplasmic) domain that contains the kinase. The kinases typically are found in an autoinhibited, inactive form. Binding of a signaling molecule leads to structural changes, followed by activation and autophosphorylation of the receptor, thereby activating the signaling pathway.

The structure of autoinhibited FLT3 (right) reveals the kinase domain (violet) folded into the typical bilobal kinase fold tethered to

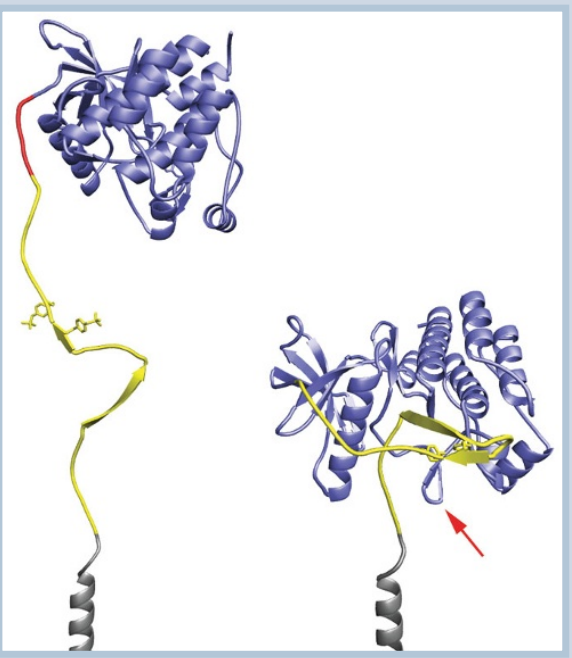

the membrane-spanning helix (modeled, gray) via the juxtamembrane (JM) domain (yellow). The JM domain contains two $\beta$ strands, one of which interacts with a small $\beta$-sheet structure of the activation loop (indicated by red arrow). This 'closed' conformation of the activation loop is characteristic of other structures of inactive kinases. In its inactivated form, the JM domain also interacts with both the $\mathrm{N}$-terminal and $\mathrm{C}$-terminal lobes of the kinase domain, stabilizing the inactive kinase conformation.

Mutations within $f / t 3$ are associated with acute myelogenous leukemia and myelodysplastic syndrome, presumably leading to disease by constitutive activation of FLT3. One of these activating mutations, internal tandem duplications (ITDs) that result in the insertion of anywhere from 4 to 68 additional residues at the $\mathrm{C}$-terminal end of the $\mathrm{JM}$ domain, is known to allow FLT3 to adopt an active conformation in the absence of ligand binding (modeled, left; ITD is shown in red). The ITD insertion would shift the position of the JM domain relative to the kinase domain, lessen the stabilizing effects of the JM domain and allow for a conformational shift to the activated form of FLT3.

Although we're still a long way from identifying a Gleevec-esque inhibitor for FLT3, the structure reported by Griffith, et al. offers valuable insight into the specific contributions of the JM domain in autoinhibition and how disease-linked ITD insertions could lead to constitutive activation.
Elizabeth Grzymski 